\section{Changes in subcellular localization of visfatin in human colorectal HCT-116 carcinoma cell line after cytochalasin-B treatment}

\author{
R.J. Bułdak, ${ }^{1}$ M. Skonieczna, ${ }^{2}$ Ł. Bułdak, ${ }^{3}$ \\ N. Matysiak, ${ }^{4}$ Ł. Mielańczyk, ${ }^{4}$ \\ G. Wyrobiec, ${ }^{4}$ M. Kukla, ${ }^{5}$ M. Michalski, ${ }^{4}$ \\ K. Żwirska-Korczala'
}

'Medical University of Silesia, School of Medicine with the Division of Dentistry, Department of Physiology, Zabrze 2Silesian University of Technology, Institute of Automatic Control,

Biosystems Group, Department of

Automatics, Electronics and Informatics,

Gliwice

${ }^{3}$ Medical University of Silesia, School of

Medicine, Department of Internal Medicine

and Clinical Pharmacology, Katowice

${ }^{4}$ Medical University of Silesia, School of

Medicine with the Division of Dentistry,

Department of Histology and

Embryology in Zabrze,

${ }^{5}$ Medical University of Silesia, School of

Medicine, Department of

Gastroenterology and Hepatology,

Katowice, Poland

\section{Abstract}

The aim of the study was to assess the expression and subcellular localization of visfatin in HCT-116 colorectal carcinoma cells after cytokinesis failure using Cytochalasin B (CytB) and the mechanism of apoptosis of cells after CytB. We observed translocation of visfatin's antigen in cytB treated colorectal carcinoma HCT-116 cells from cytosol to nucleus. Statistical and morphometric analysis revealed significantly higher area-related numerical density visfatin-bound nano-golds in the nuclei of cytB-treated HCT-116 cells compared to cytosol. Reverse relation to visfatin subcellular localization was observed in un-treated HCT116 cells. The total amount of visfatin protein and visfatin mRNA level in HCT-116 cells was also decreased after CytB treatment. Additionally, CytB significantly decreased cell survival, increased levels of $\mathrm{G} 2 / \mathrm{M}$ fractions, induced bi-nuclei formation as well as increased reactive oxygen species (ROS) level in HCT-116 cells. CytB treatment showed cytotoxic effect that stem from oxidative stress and is connected with the changes in the cytoplasmic/nuclear amount of visfatin in HCT-116 cells.

\section{Introduction}

Obesity and related metabolic diseases are associated with increased risk of cancer, such as: colorectal, ${ }^{1}$ breast $^{2-5}$ and other types of cancer. ${ }^{6,7}$ Some adipose tissue-derived hormones (adipocytokines), such as visfatin affect cell proliferation and disease progression in vitro and in vivo. ${ }^{1,8-}$ ${ }^{11}$ Visfatin has recently been established as a novel adipocytokine that is predominantly expressed in subcutaneous and visceral fat. ${ }^{12-14}$ Overexpression of visfatin was also noted in cancer cells which resulted in poor prognosis of cancer patients. ${ }^{10,15,16}$ Recent studies have shown that circulating visfatin levels are increased in the serum of colorectal cancer patients. ${ }^{16}$ Increased expression of visfatin was also confirmed in ovarian cancer ${ }^{17}$ malignant astrocytoma, ${ }^{10}$ human prostate cancer cell lines, LNCaP (androgen-sensitive) and PC3 (androgen-insensitive) ${ }_{11}^{11}$ as well as human colorectal cancer cells. ${ }^{1,8}$ Recently, it was shown that elevated serum visfatin levels were associated with postmenopausal breast cancer $(\mathrm{PBC})$ risk independently from other known risk factors for PBC..$^{18}$ Moreover, Dalamaga et al. have investigated the potential use of serum visfatin levels in patients with postmenopausal breast cancer and found that visfatin may be a promising biomarker for PBC. ${ }^{19}$ Only few studies have investigated the subcellular localization of visfatin in proliferating and non-proliferating cells (after cytokinesis or kariokinesis block) in order to establish the role of intracellular visfatin in cell cycle control. ${ }^{20-22}$

Immunoelectron microscopy is a powerful tool for localization and quantification of antigens at the ultrastructural level. Molecules of interest can be detected using colloidal nanogold conjugated antibodies. Due to specific properties (spherical shapes and high electron density) gold particles can easily be identified and counted, therefore the post-embedding approach offers possibilities for quantification study. ${ }^{23}$ Cytochalasin-B (CytB) is a known inhibitor of actin polymerization. It prevents separation of daughter cells after mitosis and leads to bi-nucleated cells (BN) Most BN cells undergo apoptosis due to cytokinesis block. In this context, anti-mitotic drugs such as cytochalasin-B are in use at the clinic. We tried to explore the association between visfatin/Nampt distribution in subcellular compartments and increased apoptosis in cells treated with $\mathrm{CytB} .{ }^{24}$

\section{Materials and Methods}

\section{Cell culture}

A human colorectal HCT-116 carcinoma cell line was obtained from the American Type
Correspondence: Dr. Rafał Jakub Bułdak, Department of Physiology, Medical University of Silesia, Jordana St. 19, 41-808 Zabrze, Poland. Tel/Fax: +48.32.2722362.

E-mail: rbuldak@sum.edu.pl

Key words: Visfatin, cytochalasin B, immunogold labeling, TEM, adipocytokines.

Contributions: BRJ, research conception and plan, manuscript editing, intracellular ROS evaluation, cell culture, statistical analysis, preparation of revised manuscript; SM, visfatin expression in human colorectal HCT-116 carcinoma cells, flow cytometry analysis, apoptosis and binucleated cells detection, cytotoxicity assay, preparation of revised manuscript (flow cytometry analysis); BŁ, language and correction, partly statistical analysis, preparation of revised manuscript; MN, MŁ, conventional EM sample preparation, immunogold labeling, EM photos preparation, preparation of revised manuscript (TEM microphotographs); WG, preparation of figures and tables; KM, preparation of figures and references, language correction; MM, quantification of immunogold particles; KŻK, project supervisor.

Conflict of interests: the authors declare no conflict of interests.

Fundings: this study was supported by grants from Silesian Medical University in Katowice, Poland. Grant number: KNW-2-009/N/3/N. The experiments were performed in the Biotechnology Center of the Silesian University of Technology in Gliwice and Silesian Medical University in Katowice using equipment financed by the Silesian Biofarma with infrastructure supported by POIG.02.03.01-24-099/13 grant: GCONiI - UpperSilesian Center for Scientific Computation.

Received for publication: 7 April 2014.

Accepted for publication: 24 June 2014.

This work is licensed under a Creative Commons Attribution NonCommercial 3.0 License (CC BYNC 3.0).

(C) Copyright R.J. Butdak et al., 2014

Licensee PAGEPress, Italy

European Journal of Histochemistry 2014; 58:2408 doi:10.4081/ejh.2014.2408

Culture Collection (ATCC) as a kind gift from Magdalena Skonieczna (Silesian University of Technology). HCT-116 cells were plated at the density of $1 \times 10^{6}$ cells per $25 \mathrm{~cm}^{2}$ flask and cultured in the McCoy $5 \mathrm{~A}$ modified medium (Sigma-Aldrich, St. Louis, M0, USA) supplemented with $10 \%$ fetal bovine serum (Gibco, North Androver, MA, USA), antibiotics: penicillin $(10,000 \mathrm{U} / \mathrm{mL})$, streptomycin $(10,000$ $\mu \mathrm{g} / \mathrm{mL}$ ), amphotericin B $(2.5 \mu \mathrm{g} / \mathrm{mL}$ ) (SigmaAldrich) under the atmosphere of $95 \%$ air and $5 \% \mathrm{CO}_{2}$ at $37^{\circ} \mathrm{C}$. HCT-116 cell line was free of mycoplasma, pathogenic viruses and bacteria. 
Cultures were maintained for no longer than four weeks after recovery from the frozen stock.

\section{Subcellular localization of visfatin/PBEF}

Processing of cells for electron tomography, conventional chemical fixation and LR White embedding

Culture of HCT-116 cells were centrifuged at $0.355 \mathrm{x}$ g for $3 \mathrm{~min}$ and the supernatant was removed, afterwards the pellet was fixed in a $2 \%(\mathrm{w} / \mathrm{v})$ formaldehyde and $0.2 \%(\mathrm{v} / \mathrm{v})$ glutaraldehyde in $0.1 \mathrm{M}$ PBS (pH 7.4, SigmaAldrich) for $90 \mathrm{~min}$ at room temperature. Then the cells were washed several times in PBS, after the last washing the pellet in PBS was warmed to $37^{\circ} \mathrm{C}$ and the same volume of $2 \%$ low gelling temperature agarose (type VII, Sigma-Aldrich) was quickly added to the cell suspension and placed in a refrigerator for 30 min. The hardened agarose blocks were cut under PBS into small pieces and dehydrated in graded ethanol series (50\%, 70\%, 90\% and 96\%; 30 min each) and infiltrated in 2:1 (v:v) and 1:2 (v:v) ethanol/LR White mixture, $30 \mathrm{~min}$ each on ice. Then the samples were infiltrated in pure LR White (Polysciences Inc., Warrington, PA, USA), after $2 \mathrm{~h}$ the resin was exchanged and allowed to stand overnight at $4^{\circ} \mathrm{C}$. The resin was exchanged again on the next day and after $2 \mathrm{~h}$ the samples were placed into gelatin capsules and polymerized for $48 \mathrm{~h}$ at $50^{\circ} \mathrm{C}$. Afterwards, thin sections with white interference color (70-100 nm) were cut using ultramicrotome OmU 3 (Reichert, Vienna, Austria) equipped with a diamond knife ( $45^{\circ}$; Diatom AG, Biel, Switzerland). The sections were mounted on Formvar coated 200 mesh nickel grids (Polysciences Inc.) and immunolabelled.

\section{Immunogold labeling method}

The sections on grids were first pre-incubat- ed for $30 \mathrm{~min}$ by floating on drops of $50 \mathrm{mM}$ $\mathrm{NH}_{4} \mathrm{Cl}$ in $\mathrm{PBS}$, subsequently blocked for $30 \mathrm{~min}$ on drops of 1\% BSA in PBS. This was followed by incubation overnight $(16-18 \mathrm{~h})$ at $4^{\circ} \mathrm{C}$ with mouse antihuman visfatin (AbD Serotec, Okford, UK) antibody diluted 1:50 in PBS. Then the grids were washed on drops of PBS (five changes, 3 min each) and bound antibodies were localized by incubating the sections for $1 \mathrm{~h}$ on immunogold-labeled goat antimouse IgG 15 nm (BBI Solutions, Madison, WI, USA) also diluted in PBS (1:100). Finally, grids were washed on drops of PBS (five changes, 5 min each) and distilled water (three changes, 3 min each) before staining with $0.5 \%$ aqueous uranyl acetate and lead citrate using EM AC 20 stainer (Leica, Vienna, Austria). In controls, the primary antibody was omitted. All incubations, except for the primary antibody step, were carried out at room temperature. Subsequently the grids were air-dried and examined under FEI Tecnai G² BioTWIN transmission electron microscope at $120 \mathrm{kV}$ (FEI, Netherlands). Images were captured with Morada CCD camera (Olympus, Hamburg, Germany).

\section{Quantification of immunogold particles}

Statistical analysis was performed on six grids from 3 independent experiments per experimental group (HCT-116 cells treated and un-treated with $\mathrm{CytB}$ ) for visfatin labeling. ImageJ (http://rsbweb.nih.gov/ij) was used to count immunogold particles and to measure areas of cytoplasm and nucleus of each HCT116 cell. Cells and nuclear envelope were outlined, the colloidal gold particles in each cell (separately cytoplasm and nucleus) were counted manually by an observer who was blind to the identity of the grids. The number of colloidal gold particles was counted in all selected areas at the same magnification ( $x$ $16,000)$. After calculating the area-related numerical densities of gold nanoparticles, statistical analysis was performed by taking the mean number of colloidal gold particles in different cell's compartments (cytosol and nucleus) and the area-related numerical density of gold nanoparticles was expressed as mean ${ }_{ \pm}$SD per cell's cytosol or nucleus as well as a mean \pm SD relative cells' cytosol or nucleus area per $100 \mu \mathrm{m}^{2}$ of the respective area.

\section{Statistical analysis}

The normality of distribution was checked using Shapiro-Wilk's test. According to variables distribution the following tests were used. Statistical significance was evaluated using ANOVA test with Scheffe's corrections or Kolmogarov-Smirnov's test with Bonferroni test. Comparisons between control and study groups were performed by $t$-test or MannWhittney U tests. The differences were considered as a statistically significant if $\mathrm{P}<0.05$.

\section{Visfatin expression in human colorectal HCT-116 carcinoma cells}

\section{RNA extraction and RT-PCR}

Total RNA from HCT 116 cells was extracted with TRI Reagent according to the manufacturer's procedure (Sigma-Aldrich). Real time RTPCR reaction was used to quantify visfatin expression in HCT-116 cell line. Reverse transcription of $100 \mathrm{ng}$ total RNA was performed on CFX 96 Touch $^{\mathrm{TM}}$ RT-PCR detection system (BioRad, Poland) using TranScriba kit (A\&A Biotechnology, Gdynia, Poland). Real time RTPCR reaction was executed for human visfatin gene using set of primers: forward GGTCTGGAATACAAGTTACATGATTTTG and reverse TTGAAGTTAACCAAGTGAGCAGATG; and for reference human GAPDH gene: forward TGCACCACCAACTGCTTAGC; and reverse GGCATGGACTGTGGTCATGAG. Real-Time 2x PCR Master Mix SYBR A (A\&A Biotechnology) mixture with cDNA and set of primers were prepared, according to the manufacturer proto-

Table 1. Cell compartment area and the amount of visfatin antigen per $100 \mu \mathrm{m}^{2}$ surface area of HCT-116 cells in cytB-treated cells $(3$ and $5 \mu \mathrm{g} / \mathrm{mL}$ ) and untreated cultures. Data represent mean cell's surface area presented in $\mu \mathrm{m}^{2} \pm S D$ and mean amount of immunogold visfatin-bounded particles per $100 \mu \mathrm{m}^{2}$ surface area (cytosol, nucleus) in tested cells. Cytoplasm area was obtained from the subtraction of nuclear area from total cell area.

\begin{tabular}{|c|c|c|c|c|c|c|}
\hline & $\begin{array}{l}\text { Cell surface } \\
\text { area }\left(\mu \mathrm{m}^{2}\right)\end{array}$ & $\begin{array}{c}\text { Cell nucleus } \\
\text { surface area } \\
\left(\mu \mathrm{m}^{2}\right)\end{array}$ & $\begin{array}{l}\text { Cell cytosol } \\
\text { surface area } \\
\left(\mu \mathrm{m}^{2}\right)\end{array}$ & $\begin{array}{l}\text { Amount of visfatin } \\
\text { antigen in nucleus } \\
/\left(\mu \mathrm{m}^{2}\right)\end{array}$ & $\begin{array}{l}\text { Amount of visfatin } \\
\text { antigen } \\
\text { in cytosol/100 } \mathrm{um}^{2}\end{array}$ & $\begin{array}{l}\text { Total amount of visfatin } \\
\text { antigen } / 100 \mu \mathrm{m}^{2}\end{array}$ \\
\hline Control MN cells & $57.8 \pm 8.1$ & $27 \pm 2.1$ & $30.7 \pm 10.9$ & $1470 \pm 326$ & $2340 \pm 523$ & $3810 \pm 340$ \\
\hline $\begin{array}{l}\text { Cytochalasin B } \\
(3 \mu \mathrm{g} / \mathrm{mL}) \\
\text { BN cells }\end{array}$ & $132.2 \pm 10.4^{*}$ & $53.9 \pm 4.2^{*}$ & $78.2 \pm 9.0^{*}$ & $810 \pm 101^{*}$ & $640 \pm 98 *$ & $1460 \pm 99 *$ \\
\hline $\begin{array}{l}\text { Cytochalasin B } \\
(5 \mu \mathrm{g} / \mathrm{mL}) \\
\text { BN cells }\end{array}$ & $173.9 \pm 12.3^{*}$ & $67.6 \pm 5.1^{*}$ & $106.3 \pm 11.8^{*}$ & $101 \pm 33^{*}$ & $74 \pm 12 *$ & $181 \pm 14^{*}$ \\
\hline
\end{tabular}

MN, mono-nucleated (2n) diploid cells; BN, bi-nucleated (4n) tetraploid cells. ${ }^{*} \mathrm{P}<0.05$ vs control group ( $\mathrm{n}=100$ counted cells in five separate experiments). 
col. The thermal profile of reaction was as follows:

i) $95^{\circ} \mathrm{C}, 4 \mathrm{~min}$ - internal denaturation

ii) 54 cycles of:

$95^{\circ} \mathrm{C}, 30 \mathrm{~s}$

$56^{\circ} \mathrm{C}, 30 \mathrm{~s}$

$72^{\circ} \mathrm{C}, 30 \mathrm{~s}$ - fluorescence detection by CFX thermocycler (Bio-Rad, Warsaw, Poland);

iii) $52^{\circ} \mathrm{C}$ do $92^{\circ} \mathrm{C}$ - melting curve

iv) $4{ }^{\circ} \mathrm{C}$ - hold.

A relative expression ratio ( $\mathrm{R}$ ) in real-time PCR is a ratio of a target gene expressed in a sample versus a control in comparison to a reference gene. The reference gene should be a stable and secure unregulated transcript, e.g., a housekeeping gene transcript like GAPDH. For the calculation of $\mathrm{R}$, the individual realtime PCR efficiencies and the CD deviation $(\Delta \mathrm{CP})$ of the investigated transcripts must be known. Raw results from experiments were obtained by software CFX Manager 2.1 (BioRad) and relative quantification of a target gene in comparison to a reference gene was calculated after Pfaffl method:25

$$
R=\frac{\left(E_{\text {target }}\right)^{\Delta C P_{\text {target(control-sample })}}}{\left(E_{\text {ref }}\right)^{\Delta C P_{\text {ref(control-sample })}}}
$$

where:

$\mathrm{R}$ is the relative expression ratio of a target gene calculated based on $\mathrm{E}$ and the $\mathrm{CP}$ deviation of an unknown sample versus a control, and expressed in comparison to a reference gene;

$E_{\text {target }}$ is the real-time PCR efficiency of target gene transcript;

$\mathrm{E}_{\mathrm{ref}}$ is the real-time PCR efficiency of a reference gene transcript;

${ }^{\triangle \mathrm{CP}}$ target is the CP deviation of control sample of the target gene transcript;

${ }^{\Delta \mathrm{CP}}$ ref is the $\mathrm{CP}$ deviation of control - sample of reference gene transcript.

\section{Flow cytometry analysis}

Cells collected for cell cycle analysis were washed with PBS, and fixed with ice cold $70 \%$ EtOH (ethanol). Suspended cells were stored at $4^{\circ} \mathrm{C}$, no longer than one week. Prior to flow cytometry analysis ethanol was removed and cells were suspended in $50 \mu \mathrm{L}$ of fresh PBS solution. In next step RNase digestion $(100 \mathrm{ng} / \mathrm{mL})$ were performed at room temperature for $20 \mathrm{~min}$. Next propidium iodide (PI) staining (100 ng/mL, SigmaAldrich) was prepared in dark environment, 15 min before assessment by flow cytometry. Fluorescence was measured directly on a flow cytometer (Becton Dickinson ARIA III) using the PE (phycoerythrin) configuration (488 nm laser line, LP mirror 566, BP filter $585 / 42)$.

\section{Apoptosis and bi-nucleated cells detection}

For analysis of the percentage of apoptotic and bi-nucleated (BI) cells, the adherent cells were cultured on coverslips in Petri dishes for 16 to $24 \mathrm{~h}$ before CytB treatment. After CytB treatment, cells were washed twice with PBS (pH 7.4), and incubated with 4\% paraformaldehyde solution in PBS for $1 \mathrm{~h}$ at $37^{\circ} \mathrm{C}$. Then, nuclei were stained with Hoechst 33258 (2.5 $\mu \mathrm{g} / \mathrm{mL}$ ) for $30 \mathrm{~min}$. The number of apoptotic nuclei and bi-nuclei cells were counted by hemocytometer under a fluorescence microscope. At least 100 cells were examined from random fields for the calculation of apoptotic percentage and bi-nucleated cells in each treatment. Results were presented as a percent of apoptotic cells after CytB treatment (1, 3, 5 $\mu \mathrm{g} / \mathrm{mL}$ ) in culture compared to control, untreated cells.

\section{MTS-cytotoxicity assay}

Cell cytotoxicity was analyzed using the MTS assay kit (Promega, Southampton, UK) according to the manufacturer's instructions and described by kim et al. ${ }^{22}$ Briefly, $20 \mu \mathrm{L}$ of Cell Titer $96{ }^{\circledR} \mathrm{AQueous}$ One Solution Reagent containing tetrazolium compound [3-(4,5-dimethylthiazol-2yl)-5-(3-carboxymethoxyphenyl)-2-(4-sulfophenyl)-2H-tetrazolium, inner salt; MTS] and an electron coupling
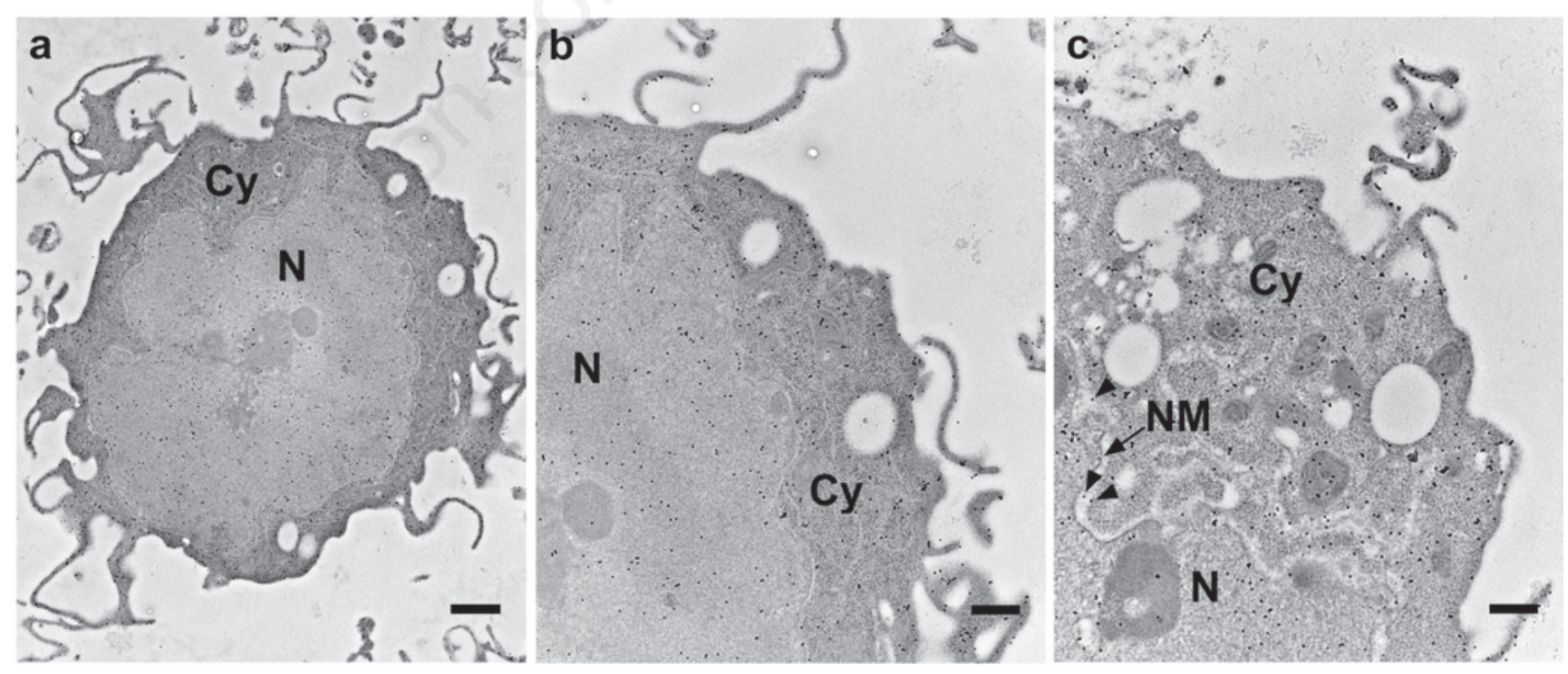

Figure 1. Subcellular visfatin distribution in human colorectal HCT-116 carcinoma cells. a,b) Ultrastructural demonstration of immunogold labelling of visfatin particles or small clusters consisting of number gold particles were demonstrated in the subcellular compartments of human colorectal HCT-116 mononucleated cells which were cultured in log phase of growth. c) Magnified view indicating visfatin labeling (arrowheads) in nuclear membrane (arrow). Cy, cytoplasm; N, nucleus; NM, nuclear membrane. Scale bars: a) $1 \mu \mathrm{m} ; \mathrm{b}, \mathrm{c}) 500 \mathrm{~nm}$. 
reagent (phenazine methosulfate; PMS) was added per well, and the cells were incubated for $1 \mathrm{~h}$ at $37^{\circ} \mathrm{C}$ in a humidified, $95 \%$ air $/ 5 \% \mathrm{CO}_{2}$ atmosphere. Formazan production by viable cells was measured at $490 \mathrm{~nm}$ using a 96 -well microplate reader $\left(\mathrm{xMark}^{\mathrm{TM}}\right.$ model no. 1681150, BioRad).

\section{Intracellular reactive oxygen species evaluation}

Intracellular reactive oxygen species (ROS) were detected in 2', 7'-dichlorodihydrofluorescein diacetate $\left(\mathrm{H}_{2} \mathrm{DCF}-\mathrm{DA}\right)$-loaded cells (Molecular Probe, Leiden, Netherlands) using a fluorescent measurement system (Model Astroscan Cytofluor 2300/2350, Applied Biosystems, Billerica, MA, USA) according to method of LeBel et al. ${ }^{26}$ Samples containing $2 \times 10^{6}$ cells were placed on Corning 6-well plates (Sigma-Aldrich) and were pre-incubated with $5 \mu \mathrm{M} \mathrm{H}_{2} \mathrm{DCF}$-DA for 1 $\mathrm{h}$ at $37^{\circ} \mathrm{C}$. The plates were centrifuged at 1200 rpm for $10 \mathrm{~min}$ and the fluorescence of control and CytB $(5 \mu \mathrm{g} / \mathrm{mL})$ treated cells was read in the Cytofluor reader (excitation at $504 \mathrm{~nm}$, emission at $526 \mathrm{~nm}$ ). The background of deacetylated, oxidised DCF (2', 7'dichlorofluorescein) was approximately 60-80 relative fluorescent units (FU), which was insignificant to the signal from specimens. ${ }^{26,27}$ As a negative control we used antioxidant $\mathrm{N}$-acetylocysteine; (NAC); (5 $\mathrm{mM}$ ) added $3 \mathrm{~h}$ prior to cytB treatment.

\section{Results}

\section{Cytochalasin-B treatment caused} changes in the subcellular localization of visfatin in human colorectal HCT-116 cells

Immunogold staining for TEM was performed to detect the subcellular localization of visfatin in the human colorectal HCT-116 carcinoma cells after cytB treatment. Area-adjusted density of immunogold particles in cytosol and nuclear compartments was also analyzed. The subcellular distribution of visfatin/PBEF in human colorectal HCT-116 cells was examined using antibodies raised against a peptide corresponding to the carboxyl-terminal 25 amino acids of human visfatin/PBEF (AbD Serotec). As shown in Table 1, human colorectal HCT116 carcinoma cells which were cultured in log phase growth, were much more immunostained in the cytoplasm than in the nucleus (Table 1), but HCT-116 cells, which had been cultured for $24 \mathrm{~h}$ with cytochalasin B (3 and 5 $\mu \mathrm{g} / \mathrm{mL}$ ), were more immunostained in the nucleus than in the cytoplasm (Table 1). Moreover the total amount of visfatin antigen per $100 \mu \mathrm{m}^{2}$ surface area in cytochalasin-B treated cells $(5 \mu \mathrm{g} / \mathrm{mL})$ was also lower than in untreated cells $\left(181 \pm 14\right.$ particles per $100 \mu \mathrm{m}^{2}$ surface area $v s 3810 \pm 340$ particles per 100 $\mu \mathrm{m}^{2}$ surface area; $\mathrm{P}<0.05$ ); (Table 1). Subcellular localization of visfatin antigen in HCT-116 cells which were cultured in $\log$ phase growth and in bi-nucleated cells following CytB treatment is shown in Figures 1 and 2 , respectively.

Moreover, the statistical analysis of the number of immunogold particles per $100 \mu \mathrm{m}^{2}$ surface area of cell compartment revealed that the density of visfatin in HCT-116 mono-nucleated, untreated cells were significantly more prominently stained for visfatin in cytosol compared to nucleus $(2340 \pm 523$ particles per 100 $\mu \mathrm{m}^{2}$ surface area of cytosol vs $1470 \pm 326$ particles per $100 \mu \mathrm{m}^{2}$ surface area of nucleus; $\mathrm{P}<0.05)$. On the contrary, the amount of visfatin antigen in the cytosol of Cyt-B treated HCT-116 bi-nucleated cells was lower than in the nucleus, for CytB $(3 \mu \mathrm{g} / \mathrm{mL})$ treated cells $\left(640 \pm 98\right.$ particles per $100 \mu \mathrm{m}^{2}$ surface area of cytosol vs $810 \pm 101$ particles per $100 \mu \mathrm{m}^{2}$ surface area of nucleus; $\mathrm{P}<0.05$ ), for CytB (5 $\mu \mathrm{g} / \mathrm{mL})$ treated cells $(74 \pm 12$ particles per 100 $\mu \mathrm{m}^{2}$ surface of cytosol $v s 101 \pm 33$ particles per $100 \mu \mathrm{m}^{2}$ surface of nucleus; $\mathrm{P}>0.05$ ); (Table 1 , Figure 3). Furthermore, the total amount of visfatin antigen in each cell compartment was decreased in HCT-116 cells treated with CytB (Table 1). Table 1 shows mean cell compartment surface area and total amount of visfatin antigen per $100 \mu \mathrm{m}^{2}$ surface area (cytosol and nucleus) of CytB treated and untreated HCT116 cells.

\section{Cytochalasin-B caused G2/M cell cycle arrest in human colorectal HCT-116 carcinoma cells}

To investigate cytB on the cell cycle progres-

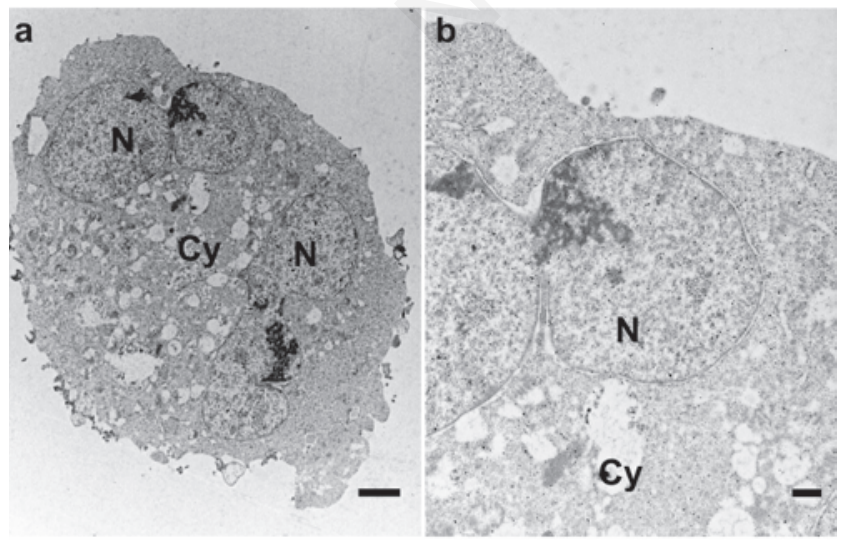

Figure 2. a) Subcellular visfatin distribution in HCT-116 binucleated cells which had been cultured for $24 \mathrm{~h}$ with cytochalasin B. b) Magnified view of (a) indicating less pronounced visfatin labeling in nucleus and cytoplasm of bi-nucleated cells. $\mathrm{Cy}$, cytoplasm; N, nucleus. Scale bars: a) $2 \mu \mathrm{m}$; b) $500 \mathrm{~nm}$.

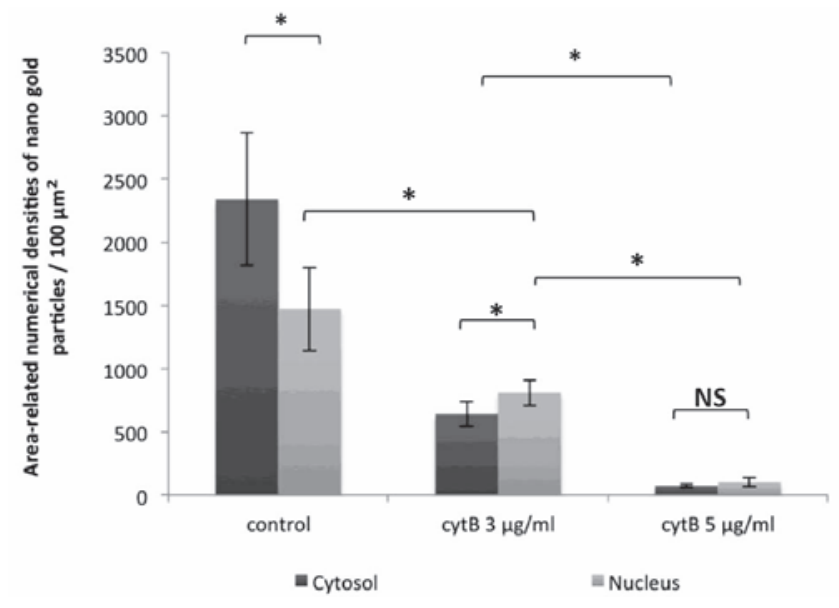

Figure 3. Statistical analysis of the area-adjusted densities of nanogold-bounded visfatin antigen per $100 \mu \mathrm{m}^{2}$ surface area of cytosol (dark grey bars) and nucleus (light grey bars) of human colorectal HCT-116 mono-nucleated cells in log phase of growth as a control and bi-nucleated HCT-116 cells after cytB treatment $(3$ and $5 \mu \mathrm{g} / \mathrm{mL}) ;{ }^{*} \mathbf{P}<0.05$; NS, not significant. 
sion, the human colorectal HCT-116 carcinoma cells were treated with cytB and cell cycle was analyzed by flow cytometry. As shown in Figure $4 \mathrm{~A}$, cytB in concentration ( 3 and $5 \mu \mathrm{g} / \mathrm{mL}$ ) decreased the G1 fractions but increased the G2/M fractions in treated cells. An increase in G2/M fractions was observed in HCT-116 cells treated with 3 and $5 \mu \mathrm{g} / \mathrm{mL}$ of cytB compared to untreated cells $(56.46 \pm 1.1$ and $56.36 \pm 5.61 \mathrm{vs}$ $37.11 \pm 5.39 \%$, respectively; $\mathrm{P}<0.05$ ). Moreover, compared to control the formation of bi-nuclei was increased in the cytochalasin B (5 $\mu \mathrm{g} / \mathrm{mL})$-treated HCT-116 cells $(46 \% \pm 4.1$ vs $11 \pm 1.4 \% ; \mathrm{P}<0.05$ ) (Figure 4B).

\section{Cytochalasin-B decreased visfatin expression in human colorectal HCT-116 carcinoma cells}

In HCT-116 cells, cytochalasin B led to a decrease in visfatin mRNA expression, whereas the differences between visfatin expression in HCT-116 cells treated with cytB $(1 \mu \mathrm{g} / \mathrm{mL})$ were statistically insignificant, when compared to cytB untreated cells as a control ( $P>0.05)$. The most pronounced decrease of visfatin mRNA expression (38\% reduction) was seen in HCT-116 cells treated with CytB ( $5 \mu \mathrm{g} / \mathrm{mL}$ ) compared to control visfatin mRNA level in cytB untreated cells (Figure 5).

\section{Cytochalasin-B treatment induced reactive oxygen species dependent apoptosis in HCT-116 cells}

Firstly, we observed a decrease in cells viability upon cytB. The most pronounced decrease in cell survival rate ( $68 \%$ of control) was noted in HCT-116 cells treated with CytB (5 $\mu \mathrm{g} / \mathrm{mL}) ; \mathrm{P}<0.05$ (Figure $6 \mathrm{~A}$ ). Secondly, we examined the percentage of apoptotic cells after CytB treatment. The percentage of HCT116 cells that underwent apoptosis following cytokinesis failure are shown in Figure 6B. The rate of apoptotic cells was increased in culture following CytB. The greatest increase in apoptosis was seen in the group treated with CytB $(5 \mu \mathrm{g} / \mathrm{mL})$ compared to cytB untreated cells $(42 \%$ vs $2 \%$ of apoptotic cells; $\mathrm{P}<0.001)$. Interestingly, HCT-116 cells, which were pre-treated with $\mathrm{NAC}(5 \mathrm{mM})$ and then a

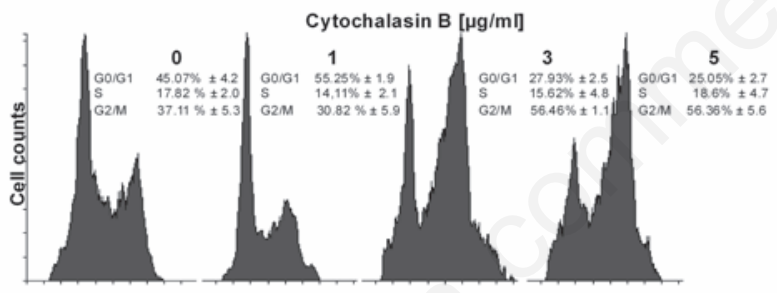

DNA content in HCT 116 cells [PI fluorescence; a.u.]

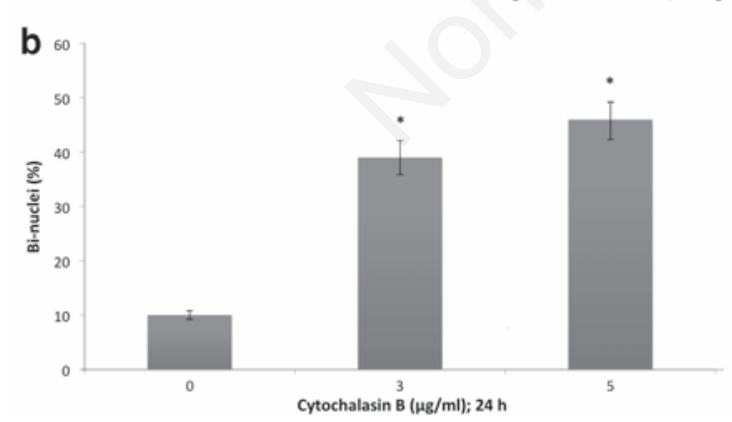

Figure 4. Effects of cytochalasin B on the cell cycle progression in human colorectal HCT-116 carcinoma cells. a) Cells treated with $0,1,3$ to $5 \mu \mathrm{g} / \mathrm{mL}$ cytochalasin B for $24 \mathrm{~h}$; at the end of treatment, cells were trypsinized and then subjected to flow cytometry analyses; the specific values represent the mean \pm SD from 3 independent repeats; charts show the result of representative experiment. b) Nuclei stained with DAPI and percentage of binuclei assessed under a fluorescence microscope; results were obtained from four experiments, data expressed as mean $\pm S D$. *Comparison between untreated samples and cytochalasin Btreated samples with the significance level $P<0.05$. subjected to CytB (5 $\mu \mathrm{g} / \mathrm{mL})$, showed reduced apoptosis rate compared to cells treated solely with CytB $(28 \%$ vs $42 \%$; $\mathrm{P}<0.05)$ (Figure $6 \mathrm{~B})$.

Figure 7 shows that the intracellular levels of ROS increased approximately $63 \%$ at $24 \mathrm{~h}$, in human colorectal HCT-116 carcinoma cells upon CytB treatment $(5 \mu \mathrm{g} / \mathrm{mL})$ when compared to control cells [195.6 \pm 14 (Relative Fluorescence Unit, R.F.U.) vs $120.5 \pm 10$ (R.F.U.); $\mathrm{P}<0.05]$. NAC (5mM) administration prior cytB $(5 \mu \mathrm{g} / \mathrm{mL})$ treatment caused significant decrease of ROS level in CytB-treated cells by $20 \%$ [ $156.3 \pm 11$ (R.F.U.) vs $195.6 \pm 14$ (R.F.U); $\mathrm{P}<0.05$ ]. Intracellular level of ROS in HCT-116 treated solely with NAC was comparable to that obtained in control cells (Figure 7).

\section{Discussion}

To the best of our knowledge, this is the first report showing changes in the subcellular localization of visfatin in the human colorectal carcinoma cells after cytokinesis failure. We used cytochalasin B (blocker of cytokinesis) to evaluate visfatin's intracellular compartment distribution in HCT-116 carcinoma cells. HCT116 cells, which maintained an exponential proliferation rate, were much more intensely immunostained against visfatin antigen in the cytoplasm than in the nucleus, but HCT-116 cells, which had been cultured for $24 \mathrm{~h}$ with cytochalasin B, were more intensly immunostained in the nucleus than in the cytoplasm. Similarly, Kitani et al. reported in 2003 that visfatin existed in both the cytoplasm and nucleus of the tested cells, and the amount of visfatin was higher in the cytoplasm than in the nucleus of proliferating PC-12 and Swiss 3T3 cells but higher in the nucleus than in the

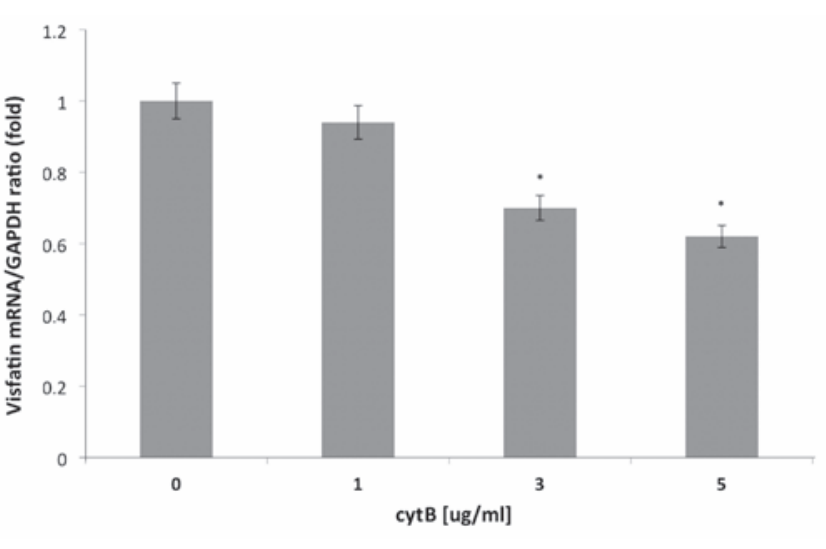

Figure 5. The effect of $\mathrm{CytB}(0,1,3,5 \mu \mathrm{g} / \mathrm{mL})$ on visfatin mRNA expression in human colorectal HCT-116 cells. Visfatin mRNA levels were determined by real time-PCR and expressed as relative values compared to basal level in control cells; $* \mathbf{P}<0.05$ vs control. 
cytoplasm of the PC-12 cells treated with nerve growth factor (NGF) and the 3T3 cells grown to a confluent state. Thus, the authors concluded that visfatin/PBEF is not a cytokine-like secreted protein but rather an intracellular protein associated with the cell cycle. ${ }^{20}$

In our study, we used CytB to block cytokinesis in tested cells to obtain bi-nucleated cells (BN cells). Cytochalasin B is well known to inhibit actin polymerization and it prevents separation of daughter cells after mitosis leading to bi-nucleated cells. ${ }^{24}$ We analyzed subcellular visfatin's antigen distribution solely in HCT-116 bi-nucleated cells treated with cytB to obtain tetraploid $(4 \mathrm{n})$ cells and compared to HCT-116 diploid (2n) cells as a control. After cytochalasin B treatment, both nucleus and cytosol surface areas of tested cells increased significantly, therefore we evaluate amount of visfatin-bounded nanogold particles distribution in these compartments per $100 \mu \mathrm{m}^{2}$ of tested surface to exclude possibility that the higher level of visfatin antigen in bi-nucleated cells was caused by increased area of cell compartments. We observed visfatin antigen translocation from cytosol to nucleus in HCT116 cells after CytB treatment, as well as decreased level of visfatin mRNA followed by above mentioned treatment. CytB results in cytokinesis block as a consequence of inhibition of actin polymerization. As an outcome we observe the karyokinesis only without cytokinesis, which lead to bi-nucleated cells, which generally are characterized by larger size. The increased surface area results from the fact that the maternal cell was prepared for the division, which may not happen. Cells prepare for the division by increasing the cytoplasm volume in order to provide sufficient organella for daughter cells.

In this case, CytB treatment also reduced cell viability, and induced G2/M-phase arrest. a

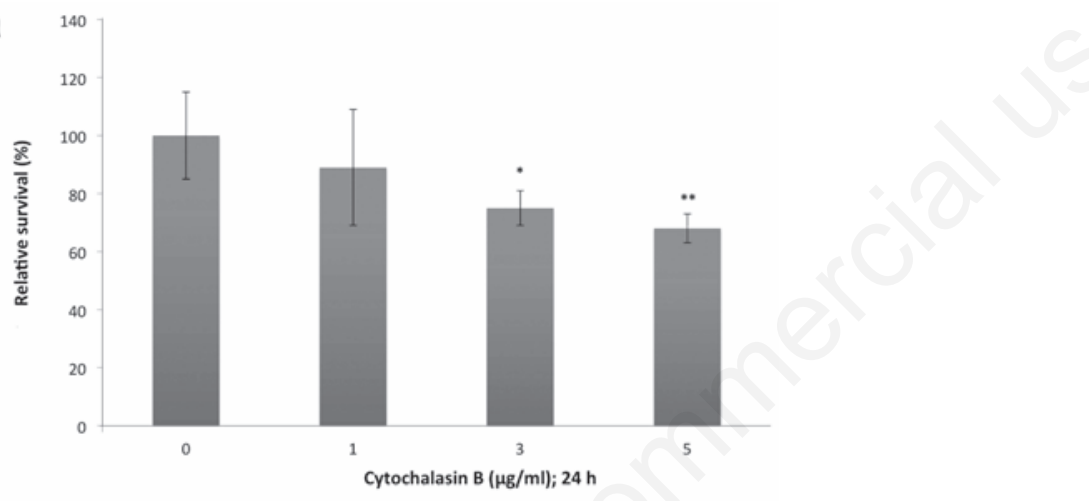

b

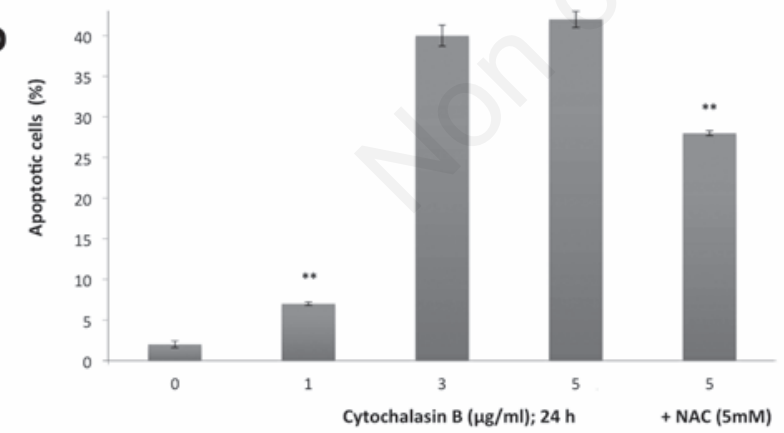

Figure 6. Viability and apoptosis ratio of human colorectal HCT116 cells after cytochalasin-B treatment. a) Cells treated with 0 , 1,3 to $5 \mu \mathrm{g} / \mathrm{mL}$ cytochalasin-B for $24 \mathrm{~h}$, cells viability quantified by MTS assay; results were obtained from seven experiments, bars represent average relative survival rate $(\%) \pm S D$ compared to control; ${ }^{*} \mathbf{P}<\mathbf{0 . 0 5}$ and ${ }^{* *} \mathbf{P}<\mathbf{0 . 0 0 1}$ indicate comparison between untreated samples and cytochalasin B-treated samples; percent of apoptotic cells in the groups treated with $\mathrm{CytB}$ solely or in combination with $\mathrm{N}$-acetylcysteine (NAC; $5 \mathrm{mM}$ ). b) Cells observed under fluorescent microscope following nuclei staining with Hoechst 33258; bars represent mean $\pm S D$ of the percentage of cytokinesis failed HCT-116 cells that underwent apoptosis; ${ }^{* *} \mathbf{P}<\mathbf{0 . 0 0 1}$ vs control.
An elevation in ROS generation was also observed. Hwang et al. showed that CytB inhibited human cervical HeLa carcinoma cell proliferation, and induced S-phase arrest and apoptosis via ROS dependent mechanism. Authors speculated that CytB activates the intrinsic apoptosis pathway by disruption of mitochondrial potential as well as activating of both caspase- 9 and $-3 .{ }^{28}$ Data obtained by Kulms et al. revealed that cytB caused apoptosis via the extrinsic pathway. ${ }^{29}$ Both studies suggest that CytB may suppress cancer cell proliferation and viability and induce apoptosis via both the intrinsic and extrinsic pathway. Our study demonstrated G2/M arrest of tested HCT-116 cells and formation of bi-nucleated cells as well as increased amount of apoptosis cells followed by cytB treatment along with visfatin translocation from cytosol to nucleus as well as decreased level of visfatin mRNA. Similarly, Chao et al. revealed that Cytochalasin B significantly decreased cell survival, inhibited cell growth, increased the levels of G2/M fractions, and induced bi-nuclei formation in lung carcinoma cells. ${ }^{30}$ Moreover, CytB was found to be capable of inducing intracellular ROS level in HCT-116 cells when examined by the cell permeable dye $\mathrm{H}_{2}$ DCF-DA. The increase of ROS level induced by CytB was reversed by addition of antioxidant: NAC (Nacetylcystein) to culture medium. Hwang et al. also demonstrated increased level of ROS in human cervical HeLa carcinoma cells followed CytB treatment. ${ }^{28}$ ROS play an important role during induction of apoptosis cell death. ${ }^{31}$ As we expected, generation of ROS in HCT-116 cells treated with CytB causes increased level of apoptotic cells in cultures. Together with apoptosis occurring after cytokinesis block we also observed a corresponding increase in the

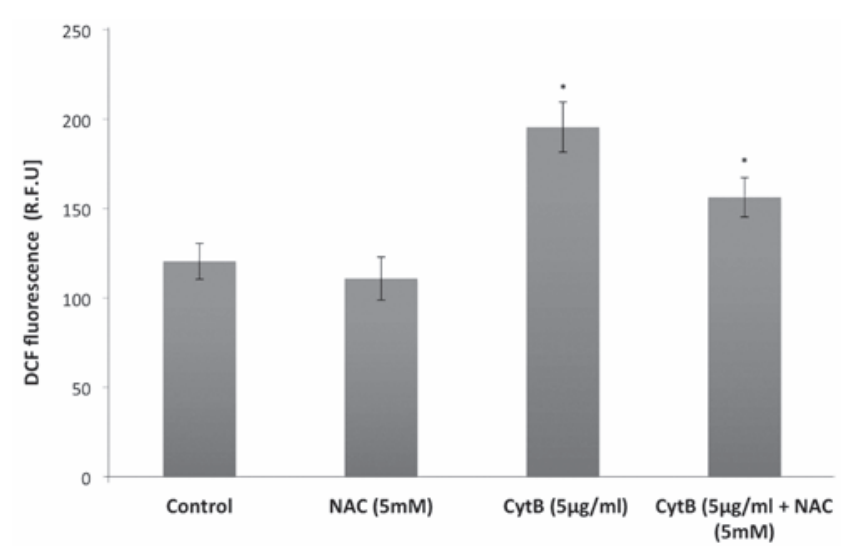

Figure 7. The effect of CytB on ROS level in human colorectal HCT-116 carcinoma cells. HCT-116 cells were treated with CytB $(5 \mu \mathrm{g} / \mathrm{mL})$ solely or in combination with NAC $(5 \mathrm{mM})$ and ROS level were detected in 2', 7'-dichlorodihydrofluorescein diacetate (H2DCF-DA)-loaded cells after $24 \mathrm{~h}$ using a fluorescent measurement system. The data are expressed as means fluorescence relative units $\pm S D, n=7 ;{ }^{*} \mathrm{P}<0.05$ vs control (untreated) cells. 
percentage of cells containing $4 \mathrm{n}$ and $>4 \mathrm{n}$ DNA content in HCT-116 cells treated with CytB compared to untreated cells (data not shown). In this case, apoptosis occurred strictly following formation of polyploid cells ( $>2 n$ ).

The greatest increase in apoptotic cells ratio and BN cells formation was seen in HCT-116 cells treated with cytB in final concentration (3 and $5 \mu \mathrm{g} / \mathrm{mL}$ ). To assess possible association between apoptotic cell death induction and ROS generation we measured oxidation of DCF in HCT-116 cells followed by CytB treatment. Treatment of DCF-loaded HCT-116 cells with CytB for $24 \mathrm{~h}$ caused increase in ROS generation (Figure 7). In the presence of the antioxidant NAC (N-acetylcysteine; $5 \mathrm{mM}$ ), a significant inhibition in the cytB-induced apoptosis and reduction in ROS level in CytBtreated cells was observed, what is shown in Figures 6 and 7, respectively. We also showed that NAC had no effect on the ROS level in CytB-untreated (control) cells. These data suggest that apoptosis induced by CytB might be partially mediated by ROS. Existing reports in the literature demonstrated that intracellular visfatin may exert Nampt enzymatic activity in some cells such as: hepatocytes, adipocytes as well as pancreatic cells. ${ }^{32}$ Nicotinamide-phosphoribosyltransferase (Nampt), converts nicotinamide (NA) to nicotinamide mononucleotide (NMN), which then reacts with ATP to regenerate $\mathrm{NAD}^{+}$. Nicotinamide adenine dinucleotide $\left(\mathrm{NAD}^{+}\right)$is an important coenzyme found in all cells that plays key roles as carrier of electrons in the redox reaction, but also as a cofactor for NAD consuming enzymes. ${ }^{33}$ Decreased level of visfatin/Nampt mRNA and subcellular translocation of this protein after CytB treatment may also explain apoptosis boost mediated by $\mathrm{NAD}^{+}$depletion. Moreover, the subtle differences seen in the visfatin/ Nampt distribution after cytokinesis failure might be important for the cell/organelle specific functions being regulated by the nicotinamide availability and remain to be explored. Visfatin/Nampt may interact with a wide array of scaffolding proteins, positive and negative catalytic regulators, signaling intermediates to membrane receptors, which might affect both its trafficking and $\mathrm{NAD}^{+}$ generation potential.

Study limitations must be kept in mind. Our experiments were performed in an in vitro environment, which may not reflect the myriad of interactions in the tumor in vivo. Additionally, immunogold labeling method does not provide the detailed information regarding protein amount as a result of only partial antigen representation in this method. However in order to confirm the alterations in the expression of the visfatin we have conducted RT-QPCR experiments which showed concurrent findings.
In conclusions, CytB treatment showed cytotoxic effect that stem from oxidative stress and is connected with the changes in the cytoplasmic/nuclear amount of visfatin in tested cells.

\section{References}

1. Van Beijnum JR, Moerkerk PTM, Gerbers AJ, De Bruine AP, Arends J-W, Hoogenboom HR, et al. Target validation for genomics using peptide-specific phage antibodies: a study of five gene products overexpressed in colorectal cancer. Int $\mathrm{J}$ Cancer J Int Cancer 2002;101:118-27.

2. Rose DP, Gilhooly EM, Nixon DW. Adverse effects of obesity on breast cancer prognosis, and the biological actions of leptin. Int J Oncol 2002;2:1285-92.

3. Nkhata KJ, Ray A, Schuster TF, Grossmann ME, Cleary MP. Effects of adiponectin and leptin co-treatment on human breast cancer cell growth. Oncol Rep 2009;21:1611-9.

4. Jarde T, Caldefie-Chezet F, GoncalvesMendes N, Mishellany F, Buechler C, Penault-Llorca $\mathrm{F}$, et al. Involvement of adiponectin and leptin in breast cancer: clinical and in vitro studies. Endocr Relat Cancer 2009;16:1197-210.

5. Tworoger SS, Eliassen AH, Kelesidis T, Colditz GA, Willett WC, Mantzoros CS, et al. Plasma adiponectin concentrations and risk of incident breast cancer. J Clin Endocrinol Metab 2007;92:1510-6.

6. Schlienger JL, Luca F, Vinzio S, Pradignac A. [Obesity and cancer].[Article in French]. Rev Med Interne 2009;30:776-82.

7. Thomas CC, Wingo PA, Dolan MS, Lee NC, Richardson LC. Endometrial cancer risk among younger, overweight women. Obstet Gynecol 2009;114:22-7.

8. Hufton SE, Moerkerk PT, Brandwijk R, de Bruine AP, Arends JW, Hoogenboom HR. A profile of differentially expressed genes in primary colorectal cancer using suppression subtractive hybridization. FEBS Lett 1999;463:77-82.

9. Folgueira MAAK, Carraro DM, Brentani H, Patrao DF da C, Barbosa EM, Netto MM, et al. Gene expression profile associated with response to doxorubicin-based therapy in breast cancer. Clin Cancer Res Off J Am Assoc Cancer Res 2005;11:7434-43.

10. Reddy PS, Umesh S, Thota B, Tandon A, Pandey P, Hegde AS, et al. PBEF1/NAmPRTase/Visfatin: a potential malignant astrocytoma/glioblastoma serum marker with prognostic value. Cancer Biol Ther 2008;7:663-8.

11. Patel ST, Mistry T, Brown JEP, Digby JE, Adya R, Desai KM, et al. A novel role for the adipokine visfatin/pre-B cell colony- enhancing factor 1 in prostate carcinogenesis. Peptides 2010;31:51-7.

12. Fukuhara A. Visfatin: A Protein Secreted by Visceral Fat That Mimics the Effects of Insulin. Science 2005;307:426-30.

13. Berndt J, Kloting N, Kralisch S, Kovacs P, Fasshauer M, Schon MR, et al. Plasma visfatin concentrations and fat depot-specific mRNA expression in humans. Diabetes. 2005 0ct;54(10):2911-6.

14. Tanaka M, Nozaki M, Fukuhara A, Segawa $\mathrm{K}$, Aoki N, Matsuda M, et al. Visfatin is released from 3T3-L1 adipocytes via a nonclassical pathway. Biochem Biophys Res Commun 2007;359:194-201.

15. Nakajima TE, Yamada Y, Hamano T, Furuta K, Gotoda T, Katai H, et al. Adipocytokine levels in gastric cancer patients: resistin and visfatin as biomarkers of gastric cancer. J Gastroenterol 2009;44:685-90.

16. Nakajima TE, Yamada Y, Hamano T, Furuta K, Matsuda T, Fujita S, et al. Adipocytokines as new promising markers of colorectal tumors: adiponectin for colorectal adeno$\mathrm{ma}$, and resistin and visfatin for colorectal cancer. Cancer Sci 2010;101:1286-91.

17. Shackelford RE, Bui MM, Coppola D, Hakam A. Over-expression of nicotinamide phosphoribosyltransferase in ovarian cancers. Int J Clin Exp Pathol 2010;3:522-7.

18. Dalamaga M, Karmaniolas K, Papadavid E, Pelekanos N, Sotiropoulos G, Lekka A. Elevated serum visfatin/nicotinamide phosphoribosyl-transferase levels are associated with risk of postmenopausal breast cancer independently from adiponectin, leptin, and anthropometric and metabolic parameters. Menopause NYN 2011;18:1198-204.

19. Dalamaga M, Archondakis S, Sotiropoulos G, Karmaniolas K, Pelekanos N, Papadavid $\mathrm{E}$, et al. Could serum visfatin be a potential biomarker for postmenopausal breast cancer? Maturitas 2012;71:301-8.

20. Kitani T, Okuno S, Fujisawa H. Growth phase-dependent changes in the subcellular localization of pre-B-cell colonyenhancing factor. FEBS Lett 2003;544:74-8.

21. Thakur BK, Lippka Y, Dittrich T, Chandra P, Skokowa J, Welte K. WAMPTpathway is involved in the FOX03a-mediated regulation of \GADD45A expression. Biochem Biophys Res Commun 2012;420:714-20.

22. Kim JG, Kim E0, Jeong BR, Min YJ, Park JW, Kim ES, et al. Visfatin stimulates proliferation of MCF-7 human breast cancer cells. Mol Cells 2010;30:341-5.

23. Baschong W, Stierhof YD. Preparation, use, and enlargement of ultrasmall gold particles in immunoelectron microscopy. Microsc Res Tech 1998;42:66-79.

24. Fenech M. Cytokinesis-block micronucleus 
cytome assay. Nat Protoc 2007;2:1084-104.

25. Pfaffl MW. A new mathematical model for relative quantification in real-time RTPCR. Nucleic Acids Res 2001 1;29:e45.

26. LeBel CP, Ischiropoulos H, Bondy SC. Evaluation of the probe 2',7'-dichlorofluorescin as an indicator of reactive oxygen species formation and oxidative stress. Chem Res Toxicol 1992;5:227-31.

27. Bułdak RJ, Polaniak R, Bułdak L, ZwirskaKorczala K, Skonieczna M, Monsiol A, et al. Short-term exposure to $50 \mathrm{~Hz}$ ELF-EMF alters the cisplatin-induced oxidative response in AT478 murine squamous cell carcinoma cells. Bioelectromagnetics 2012;33641-51.
28. Hwang J, Yi M, Zhang X, Xu Y, Jung JH, Kim D-K. Cytochalasin B induces apoptosis through the mitochondrial apoptotic pathway in HeLa human cervical carcinoma cells. Oncol Rep 2013;30:1929-35.

29. Kulms D, Düssmann H, Pöppelmann B, Ständer S, Schwarz A, Schwarz T. Apoptosis induced by disruption of the actin cytoskeleton is mediated via activation of CD95 (Fas/AP0-1). Cell Death Differ 2002;9:598-608.

30. Chao J-I, Liu H-F. The blockage of survivin and securin expression increases the cytochalasin B-induced cell death and growth inhibition in human cancer cells. Mol Pharmacol 2006;69:154-64.
31. Fleury C, Mignotte B, Vayssière J-L. Mitochondrial reactive oxygen species in cell death signaling. Biochimie 2002;84: 131-41.

32. Revollo JR, Korner A, Mills KF, Satoh A, Wang T, Garten A, et al. Nampt/PBEF/ Visfatin regulates insulin secretion in beta cells as a systemic NAD biosynthetic enzyme. Cell Metab 2007;6: 363-75.

33. Busso N, Karababa M, Nobile M, Rolaz A, Van Gool F, Galli M, et al. Pharmacological inhibition of nicotinamide phosphoribosyltransferase/visfatin enzymatic activity identifies a new inflammatory pathway linked to NAD. PloS One 2008;3:e2267. 